\title{
The Comparison of Mental Rotation Performances and Academic Achievements in Students of the Faculty of Sport Sciences and Education Sciences
}

\author{
Şenay Şahin ${ }^{1}$, Ersin Şahin ${ }^{2}$, Engin Sağdilek ${ }^{3}$, Şerife Vatansever ${ }^{1}$, Yakup Zühtü Birinci ${ }^{1}$, Ali Kamil Güngör ${ }^{1}$ \\ \& Erhan Kiziltan ${ }^{4}$ \\ ${ }^{1}$ Department of Coaching Education, Faculty of Sport Sciences, Bursa Uludağ University, Turkey \\ ${ }^{2}$ Department of Curriculum and Instruction, Faculty of Education, Bursa, Uludağ University, Turkey \\ ${ }^{3}$ Department of Biophysics, Faculty of Medicine, Bursa Uludağ University, Turkey \\ ${ }^{4}$ Faculty of Medicine, Başkent University, Turkey \\ Correspondence: Şenay Şahin, Assoc. Prof. Dr, http://orcid.org/0000-0002-9221-0616, Bursa Uludağ University, \\ TR-16059 Gorukle/Bursa, Turkey. E-mail: sksahin@uludag.edu.tr
}

Received: February 10, 2020 Accepted: April 2, 2020 Online Published: April 16, 2020

doi:10.5539/jel.v9n3p66 URL: https://doi.org/10.5539/jel.v9n3p66

\begin{abstract}
Mental rotation (MR) is the ability to rotate three-dimensional objects using the imagination. As the ability to generate, retrieve, maintain, and manipulate visual-spatial information, MR plays a critical role throughout education and sport. In this aspect our objective in this study was to compare MR performances and academic achievement between students of art, foreign languages (FL), computer-instructional technologies (CIT) and physical education (PE).

In the computer-based MR test, the image files of the library "Mental Rotation Stimulus Library" were used with the written permission of the author. A total of 144 participants composed of 79 males and 65 females volunteered in the study.

Comparing the academic achievements (AA) with the PE group and art, CIT, FL and control groups; it was observed that all the groups are better than PE $(p<0.05)$. However, no significant difference was found between $\mathrm{PE}$ and all groups in MR performances $(\mathrm{p}>0.05)$.

In conclusion, PE students performed similarly with other students in terms of MR, although their AA were low. MR ability is clearly related not only to problem solving, acquiring mathematical knowledge and academic thinking but also to motor abilties.
\end{abstract}

Keywords: academic achievement, education, mental rotation

\section{Introduction}

There is recently a rapid increase in knowledge in different disciplines. It is very important for the learners to select and organize the information that is meaningful and valuable from numerous informations for them, to be aware of their own thinking processes, to recognize their own deficiencies and competences, and to be systematic and planned. If the higher the thinking skills involved in learning, the more persistent the learning will be. In the process of learning and teaching, the teacher can acquire the necessary behaviors at the level of knowledge, comprehension and implementation towards these thinking skills. It is necessary to use different methods and processes in order to reach the cognitive steps including higher level analysis, synthesis and evaluation (Demir \& Doğanay 2009). A different method or practice used to activate this skillful process is mental description or mental rotation. Mental description, which is called the imagination of an object in all its details, is an important skill in performing many cognitive functions (Kızlltan et al., 2013). MR, which is a concrete expression of the ability to mentally manage, direct and process visual information in the individual's memory, is used extensively in the evaluation of visual-spatial abilities. In studies that emphasize the importance of learning and perception development, MR skill is evaluated as a skill that increases the speed of achievement and solution in subjects requiring spatial reasoning such as spatial positioning, mental navigation (Campos, 2012). 
Students who study at the faculty of education will develop their thinking skills such as perceiving and solving problems, developing strategies, making correct and quick decisions, they will be successful in their professional lives, approaching actions, and producing practical solutions to problems. Behavior gains will develop at the level of knowledge, understanding and practice (Miller \& Halpern, 2013). It is important that students reach high-level cognitive processes such as analysis, synthesis and evaluation using different methods. Another method used to develop these high-level cognitive skills is the MR that plays an important role in the development of spatial ability.

Spatial ability is defined by researchers under different names. The reason for this situation is to conduct studies between multi disciplines. In general, spatial ability can be defined as a way of thinking related to positioning, rotating, moving situations and perspective in objects. In studies conducted in different science fields, and evidence supporting a positive link between talent and performance, especially in the fields of science, technology, engineering and mathematics, have been obtained (Uttal et al., 2013).

This ability plays a role in problem solving skill (Geary et al., 2000), mathematical achievements (Hegarty \& Kozhevnikov, 1999) and the development of academic thinking skill (Peters et al., 1995). In short, MR performance is the ability to rotate three-dimensional objects using the imagination (Jansen et al., 2016; Pietsch \& Jansen, 2012). To summarize, mental rotation performance is the ability to think three-dimensional objects at different angles in spatial positioning (Jansen et al., 2016; Pietsch \& Jansen, 2012).

When the relationship between MR and AA performance is examined, it is important for researchers in the specified fields because of it includes tasks such as learning, technical drawing, geometric problem solving or molecular structure representations of chemical materials in science, technology, engineering and mathematics disciplines. Because while some researchers are designing a training program, they consider the performance of students who analyze the dynamics, structures and spatial transformations of objects in three-dimensional space (Höffler, 2010; Lohman, 1993; Stieff, 2007). As the important role of mental rotation in academic achievement is recognized, the use of spatial or mental rotation tests in educational research and practice is expected to increase (Duffy et al., 2015).

Visual spatial ability is also used in conducting studies to examine cognitive processes in the field of sport sciences. It has the task of interpreting the position of an object in space according to static or dynamic state of it (Höffler, 2010; Lohman, 1993). Visual spatial abilities is key in education and sports, as the ability to position, visualize, rotate, change, and use. From this point, our aim in this study was to compare MR performances between students of Art, CIT, FL and PE.

\section{Method}

\subsection{Participants}

A total of 144 participants composed of 79 males and 65 females volunteered in the context of the study. Mean age, weight, height, body mass index (BMI) of the participants were $22.4 \pm 2.71$ years, $68.05 \pm 15.28 \mathrm{~kg}, 171.33 \pm 9.22$ $\mathrm{cm}$. and $21.89 \pm 4.52 \mathrm{~kg} / \mathrm{m}^{2}$ respectively. Eighty-six (46 male, 40 female) university students and thirty sedantary (17 male, 13 female) who are not engaged in sports and twenty-nine (17 males, 12 female elite karate athletes) elite athletes were included in the study after being informed about the study and obtaining their consents. The non-athlete university students were selected from the faculties of Arts, CIT and FL of Bursa Uludağ University.

\subsection{Material and Procedure}

In this research, quantitative research method was used. This study was carried out using a comparative semi-experimental-control group design.

All participants in the study were asked to be at Bursa Uludağ University Faculty of Sport Sciences at 9:00 am on the day of experimental intervention. First of all, demographic information of the participants was taken and body mass index measurements were completed. Afterwards, all participants were performed MR tests on an adjustable seat in a room isolated from sound, where the light and temperature were suitable.

\subsubsection{Measurements}

Mental rotation test. MR test is a computer based test. The tests were carried out in a quiet environment. Image files of the "Mental Rotation Stimulus Library" library were used as the mental rotation data set used in the study. And the author's permission was taken. In these image files that validity and reliability have been made, each image/shape was created by adding 10 cubes end to end. Images/shapes are two-dimensional images of cubes rotated at different angles in three-dimensional space. In the test consisting of 16 questions in total, each question contained four pictures. The first one was the reference picture. Only one of the other three pictures is the same 
with the object in the reference picture, the only difference was that it was rotated in three dimensional space. As the axis of rotation in space, $\mathrm{X}$ axis was chosen in the first half of 16 questions and $\mathrm{Z}$ axis in the other half. The angle of rotation for both axes groups was chosen in increments of $30^{\circ}$ between $0-180^{\circ}$. The participant was asked to find out which of the three pictures, other than the reference picture, was the same with the reference picture as soon as possible. The response time was measured by the computer at the level of milliseconds (ms) with the record of "right", "wrong" and "incorrect operation", and stored on the computer for further analysis. The test should be completed within 5 minutes. Participants must define the correct option in the test as soon as possible and press the button. The correct answer number and total time data are evaluated (Pietsch \& Jansen, 2012).

Body mass index (BMI). BMI was recorded by a Bioelectrical Impedance Analyzer device (TANITA, TBF300 Japan).
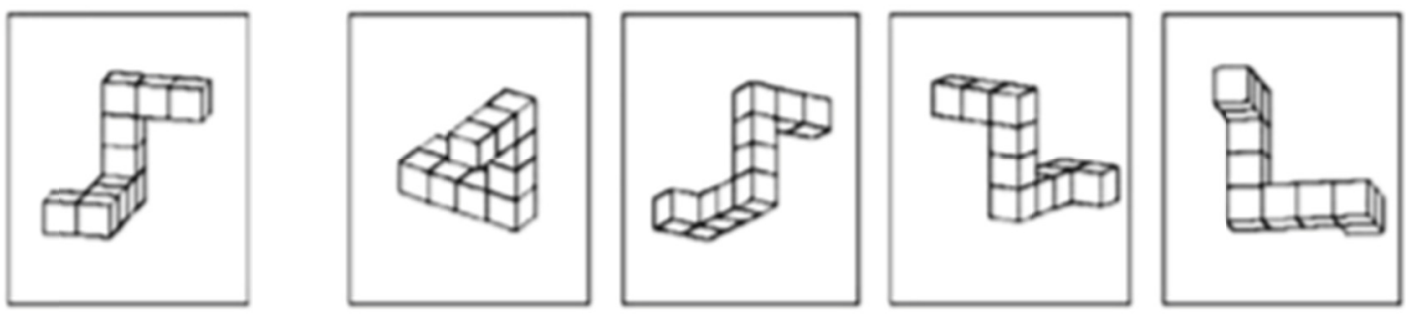

Figure 1. A question set prepared with pictures selected from library. Participants are asked to find out which of the 3 pictures on the right is the same as the object shown in the reference picture on the left

\subsection{Statictical Analysis}

The One Way ANOVA test was used to compare continuous variables between groups. Comparisons of intra-group dependent variables, were made with paired $t$ test for those which show normal distribution, and with Wilcoxon rank sum tests for those which does not show normal distribution. The Spearman test was implemented for the connections between the tests. $\mathrm{p}<0.05$ was accepted as the significance level. SPSS v. 24 program was used for statistical analyzes.

\section{Result}

Our objective in this study was to compare MR performances between students of art, FL, CIT and PE. A total of 144 participants composed of 79 males and 65 females volunteered in the context of the study. Mean age, weight, height, body mass index (BMI) of the participants were $22.4 \pm 2.71$ years, $68.05 \pm 15.28 \mathrm{~kg}, 171.33 \pm 9.22 \mathrm{~cm}$. and $21.89 \pm 4.52 \mathrm{~kg} / \mathrm{m}^{2}$ respectively (Table 1 ).

Table 1. Characteristics of the participants

\begin{tabular}{llllll}
\hline $\mathrm{N}$ & Sex & Age (years) & Weight $(\mathrm{kg})$ & Height $(\mathrm{cm})$ & $\mathrm{BMI}\left(\mathrm{kg} / \mathrm{m}^{2}\right)$ \\
144 & $79 \mathrm{M} / 65 \mathrm{~F}$ & $22.4 \pm 2.71$ & $68.05 \pm 15.28$ & $171.33 \pm 9.22$ & $21.89 \pm 4.52$ \\
\hline
\end{tabular}

Note. M: Male, F: Female, BMI: Body mass index, cm: centimetre, kg: kilogramme.

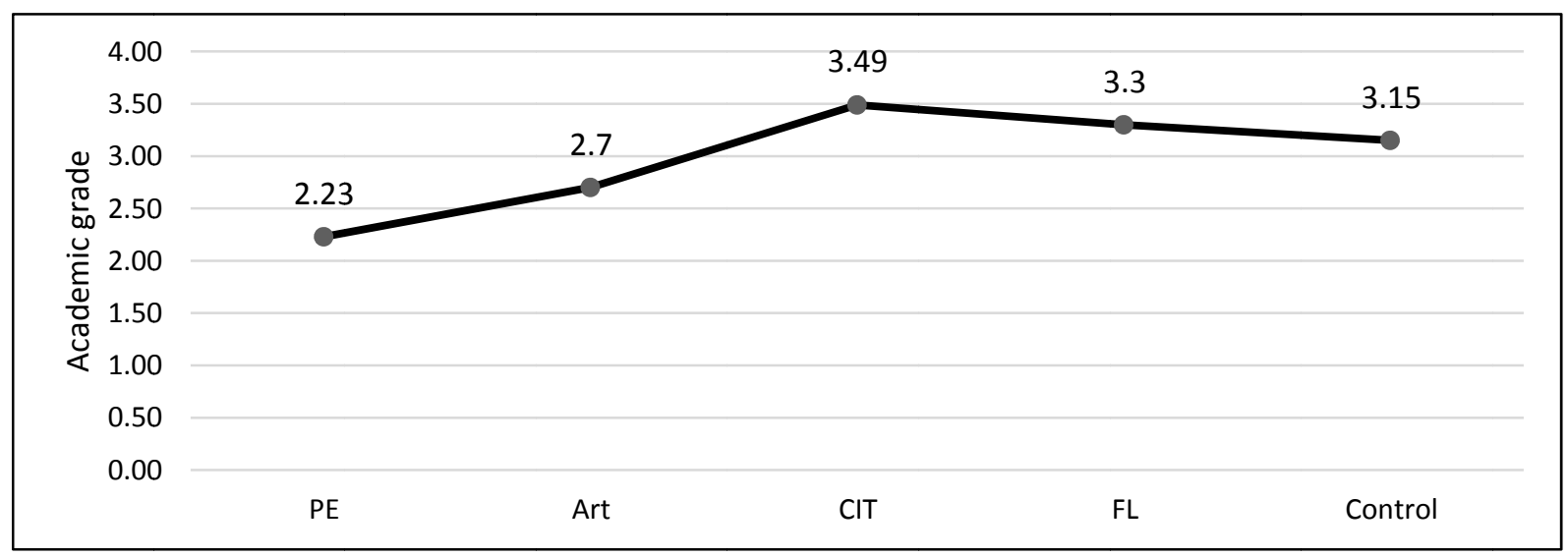

Figure 2. Groups academic achievement averages 
Comparing the academic achievements with the PE and art, CIT, FL, control groups (respectively, 2.23; 2.7; 3.49; 3.3 ; 3.15); it was observed that all the groups are higher than PE $(\mathrm{p}<0.05)$, (Figure 2).

No statistically significant difference was found between PE (9) and art (8.1), CIT (9.38), FL (10.07), control (8.23) groups in MR performances ( $p>0.05$ ), (Figure 3).

No statistically significant difference was found (Figure 4) between PE (155100 ms) and art (166571.55ms), CIT $(191328.32 \mathrm{~ms})$, FL $(178204 \mathrm{~ms})$, control $(188671 \mathrm{~ms})$ groups in total time to finish MR test $(\mathrm{p}>0.05)$, even though the AA of the PE is the lowest. And also in the MR test; the athletes completed the test earlier than the other groups, although they had statistically similar correct answer numbers.

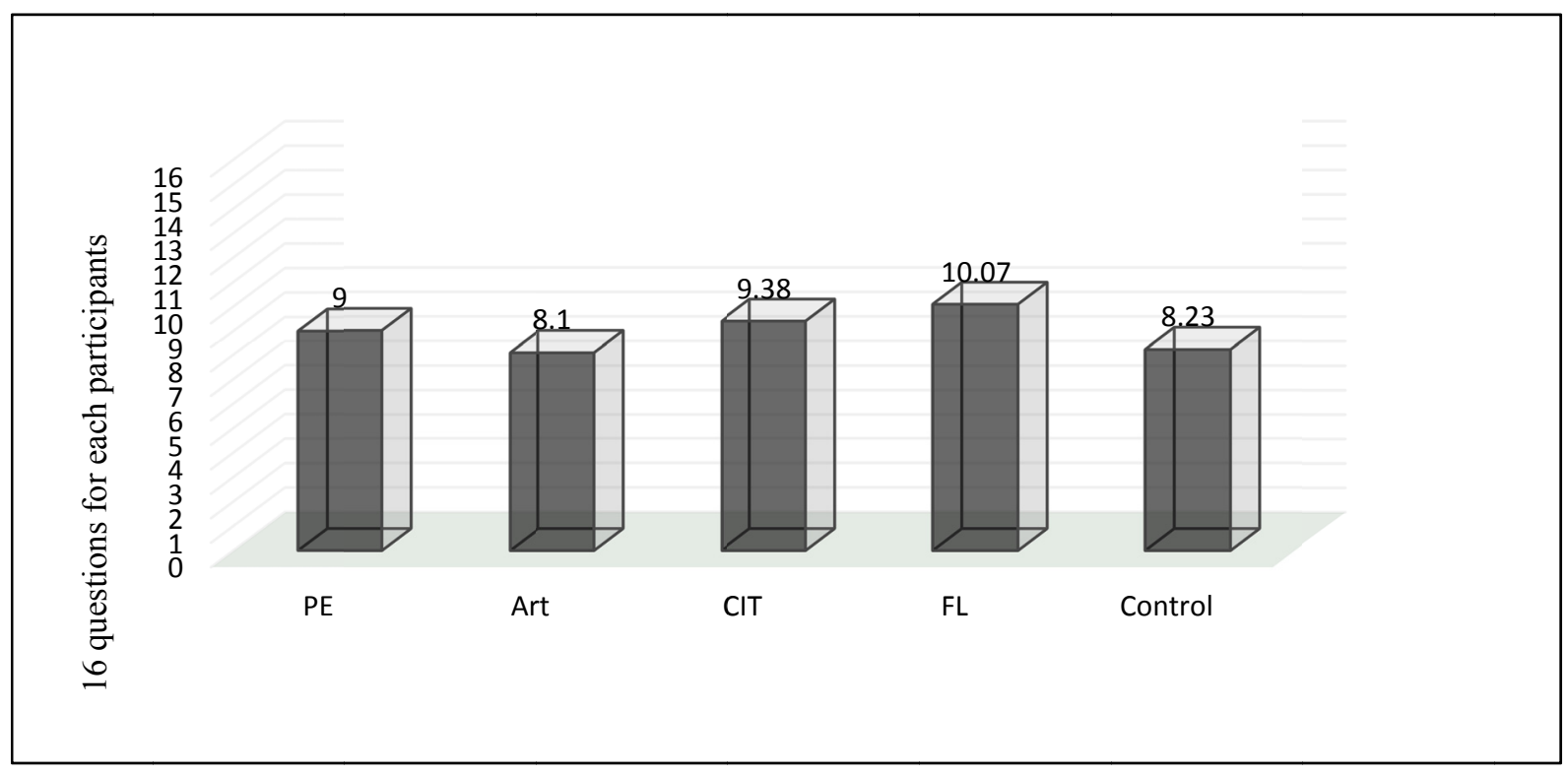

Figure 3. Correct answer averages of mental rotation test of groups

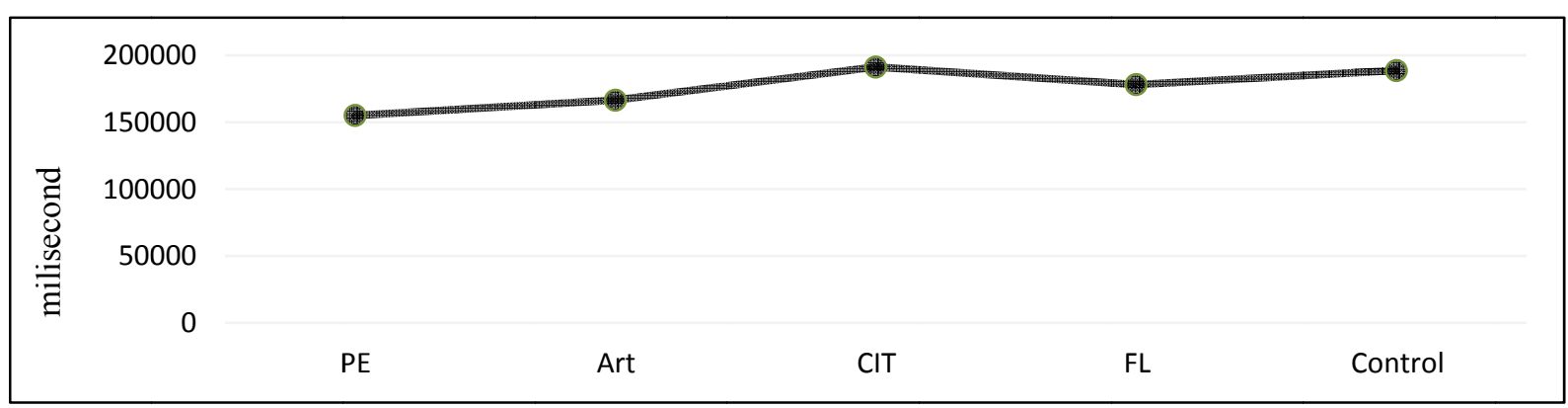

Figure 4. Participants' total time to complete mental rotation test

\section{Conclusion}

MR described as a significant cognitive skill; is the skill of skillfully positioning two or three-dimensional objects in the mind. Jordan et al. (2001) stated that activate certain parts of the brain actions involving object rotation through brain imaging, as in physical activity when mental rotation occurs. MR supports the forming movoment of motor function components and has increase the importance in recent years. Because of its importance in the development of learning and perception, which is at the center of many cognitive functions, it is considered as a skill that increases the speed of achievement and solution in issues requiring spatial reasoning. this parameter is a concrete expression of the ability to mentally management, processing and manipulate visual information in memory. When the studies were examined; Pietsch and Jansen (2012) investigated the MR performances of students in faculties of music, sports and education, reported that students studying in the faculty of music and 
sports exhibit a better MR performance than the students of the faculty of education. Ozel et al. (2002) examined the MR performance levels of gymnasts, athletes and non-athletes and reported that the MR level of gymnasts was better. Schmidt et al. (2016) studied the MR tasks of gymnasts, orienteers, doing sports people and sedentary individuals and reported that orienteers and gymnasts were more successful than non-athletes. In his study, Karagün (2018) examined the MR performances of students studying computer and physical education teaching, he found a statistically significant difference in favor of students studying computer teaching.

Jansen et al. (2009) found that there was an increase in MR performance of sedentaries exercising at least 3 days a week for 45 minutes per day. In our study, However, no statistically significant difference was found between PE and all groups in MR performances. The correct numbers (Table 1) and total time to finish (Figure 2) of the MR test are statistically similar to other groups, even though the AA of the PE is low. And also in the MR test; the PE students completed the test earlier than the other groups, although they had similar correct answer numbers. A study of Jansen, Titze and Heil (2009) found that juggling training over three months improved MR performance in adults. Jansen and Pietsch (2010) found an increased MR performance of participants after they attended a sport class for $45 \mathrm{~min}$. Our study supports the literature and shows that sport has a positive effect on MR performance. Cherney et al. (2014), Cooke and Voyer (2007), Quaiser and Lehmann (2006) also reported that the MR performance of individuals who played e-sports games such as action, strategy, cube games between 45 minutes and 2 weeks have improved. Strobach and Schubert (2014) stated that action-based computer games improved MR, spatial distribution and selectivity, rapid detection and visual memory, and improve instant decision making.

The results obtained in this study have important implications for sport and education science. For people who work in the fields of sport and education science, it is important to see that a long-time activity in these disciplines, has an enhancing effect on a specific cognitive task.

In conclusion, PE students performed similarly with other students in terms of MR, although their AA were low. MR ability is clearly related not only to problem solving, acquiring mathematical knowledge and academic thinking but also to motor abilties.

\section{Acknowledgments}

The authors would like to thank all the students who study at Faculty of Education Sciences, Uludag University by helping in data acquisition.

This article was previously presented as a paper in 17. International Sport Science Congress, Turkey.

\section{References}

Bastık, C., Sahin, Ş., Şahin, E., Pancar, S., Sağdilek, E., \& Kızıltan, E. (2018). Examination Of The Finger Tapping Test And Mental Rotation Achievement Level Of The Orienteering Athletes. European Journal of Physical Education and Sport Science.

Campos, A. (2012). Measure of the ability to rotate mental images. Psicothema, 24(3), 431-434. https://doi.org/10.1037/t14408-000

Cherney, I. D., Kyle, B., \& Joseph, S. (2014). Training spatial skills in men and women. Perceptual and Motor Skills, 119(1), 82-99. https://doi.org/10.2466/23.25.PMS.119c12z0

Cooke-Simpson, A., \& Voyer, D. (2007). Confidence and gender differences on the Mental Rotations Test. Learning and Individual Differences, 17(2), 181-186. https://doi.org/10.1016/j.lindif.2007.03.009

Demir, Ö., \& Doğanay, A. (2009). Bilişsel farkındalık becerilerinin geliştirilmesinde bilişsel koçluk yaklaşımı. Kuram ve Uygulamada Eğitim Yönetimi, 60(60), 601-624.

Duffy, G., Farrell, S., Harding, R., Behan, A., Mac Raighne, A., Howard, R., ... Bowe, B. (2015). The effects of spatial skills and spatial skills training on academic performance in STEM education.

Geary, D. C., Saults, S. J., Liu, F., \& Hoard, M. K. (2000). Sex differences in spatial cognition, computational fluency, and arithmetical reasoning. Journal of Experimental child Psychology, 77(4), 337-353. https://doi.org/10.1006/jecp.2000.2594

Hegarty, M., \& Kozhevnikov, M. (1999). Types of visual-spatial representations and mathematical problem solving. Journal of Educational Psychology, 91(4), 684. https://doi.org/10.1037/0022-0663.91.4.684

Höffler, T. N. (2010). Spatial ability: Its influence on learning with visualizations - a meta-analytic review. Educational Psychology Review, 22(3), 245-269. https://doi.org/10.1007/s10648-010-9126-7

Jansen, P., \& Pietsch, S. (2010). Physical activity improves mental rotation performance. Creative Education, 1, 58-61. https://doi.org/10.4236/ce.2010.11009 
Jansen, P., Titze, C., \& Heil, M. (2009). The influence of juggling on mental rotation performance. International Journal of Sport Psychology, 40, 351-359.

Jansen, P., Zayed, K., \& Osmann, R. (2016). Gender differences in mental rotation in Oman and Germany. Learning and Individual Differences, 51, 284-290. https://doi.org/10.1016/j.lindif.2016.08.033

Jansen-Osmann, P., \& Heil, M. (2007). Suitable stimuli to obtain (no) gender differences in the speed of cognitive processes involved in mental rotation. Brain and Cognition, 64, 217-227. https://doi.org/10.1016/j.bandc.2007.03.002

Jordan, K., Heinze, H. J., Lutz, K., Kanowski, M., \& Jäncke, L. (2001). Cortical activations during the mental rotation of different visual objects. Neuroimage, 13(1), 143-152. https://doi.org/10.1006/nimg.2000.0677

Karagün, E. (2018). Perception-Attention-Memory Reaction Time of PE Teacher and Computer Teacher Candidates. Journal of Education and Training Studies, 6(n11a), 98-104. https://doi.org/10.11114/jets.v6i11a.3805

Kızıltan, E., Yazıcı, A. C., Aktaş, G., Aladağ, A., Ergene, M., Turanoğlu, M. A., \& Yılmaz, M. S. (n.d.). Klinik Öncesi Eğitim Sürecinde Mental Rotasyon Becerilerinin Değerlendirilmesi: Başkent Üniversitesi Örneği. Tip Eğitimi Dünyası, 37(37), 1-14.

Lohman, D. F. (1993). Spatial ability and g. In I. Dennis \& P. Tapsfield (Eds.), Human abilities: Their nature and measurement (pp. 97-116).

Lubinski, D. (2010). Spatial ability and STEM: A sleeping giant for talent identification and development. Personality and Individual Differences, 49(4), 344-351. https://doi.org/10.1016/j.paid.2010.03.022

Miller, D. I., \& Halpern, D. F. (2013). Can spatial training improve long-term outcomes for gifted STEM undergraduates? Learning and Individual Differences, 26, 141-152. https://doi.org/10.1016/j.lindif.2012.03.012

Moreau, L., Clifford, B., Freire, J., Futrelle, J., Gil, Y., Groth, P., \& Plale, B. (2011). The open provenance model core specification (vo1. 1). Future Generation Computer Systems, 27(6), 743-756. https://doi.org/10.1016/j.future.2010.07.005

Newcombe, N. S. (2013). Seeing Relationships: Using Spatial Thinking to Teach Science, Mathematics, and Social Studies. American Educator, 37(1), 26.

Ozel S., Larue J., \& Molinaro, C. (2002). Relation between sport activity and mental rotation: Comparison of three groups of subjects. Perceptual and Motor Skills, 95, 1141-1154. https://doi.org/10.2466/pms.2002.95.3f.1141

Peters, M., \& Battista, C. (2008). Applications of mental rotation figures of the Shepard and Metzler type and description of a mental rotation stimulus library. Brain Cogn, 66(3), 260-264. https://doi.org/10.1016/j.bandc.2007.09.003

Peters, M., Chisholm, P., \& Laeng, B. (1995). Spatial ability, student gender, and academic performance. Journal of Engineering Education, 84(1), 69-73. https://doi.org/10.1002/j.2168-9830.1995.tb00148.x

Pietsch, S., \& Jansen, P. (2012). Different mental rotation performance in students of music, sport and education. Learning and Individual Differences, 22(1), 159-163. https://doi.org/10.1016/j.lindif.2011.11.012

Quaiser-Pohl, C., Geiser, C., \& Lehmann, W. (2006). The relationship between computer-game preference, gender, and mental-rotation ability. Personality and Individual Differences, 40(3), 609-619. https://doi.org/10.1016/j.paid.2005.07.015

Schmidt, M., Egger, F., Kieliger, M. at al. (2016). Gymnasts and orienteers display better mental rotation performance than nonathletes. Journal of Individual Differences, 37(1), 1-7. https://doi.org/10.1027/1614-0001/a000180

Shepard, R. N., \& Metzler, J. (1971). Mental rotation of three-dimensional objects. Science, 171(3972), 701-703. https://doi.org/10.1126/science.171.3972.701

Sorby, S. A. (2009). Educational research in developing 3 - D spatial skills for engineering students. International Journal of Science Education, 31(3), 459-480. https://doi.org/10.1080/09500690802595839

Stieff, M. (2007). Mental rotation and diagrammatic reasoning in science. Learning and Instruction, 17(2), 219-234. https://doi.org/10.1016/j.learninstruc.2007.01.012

Strobach, T., \& Schubert, T. (2014). Positive consequences of action-video game experience on human cognition: 
Potential benefits on a societal level. Epidemiology of online game addiction. OMICS Group.

Uttal, D. H., Meadow, N. G., Tipton, E., Hand, L. L., Alden, A. R., Warren, C., \& Newcombe, N. S. (2013). The malleability of spatial skills: A meta-analysis of training studies. Psychological Bulletin, 139(2), 352. https://doi.org/10.1037/a0028446

Uttal, D. H., Miller, D. I., \& Newcombe, N. S. (2013). Exploring and enhancing spatial thinking: Links to achievement in science, technology, engineering, and mathematics? Current Directions in Psychological Science, 22(5), 367-373. https://doi.org/10.1177/0963721413484756

Wai, J., Lubinski, D., \& Benbow, C. P. (2009). Spatial ability for STEM domains: Aligning over 50 years of cumulative psychological knowledge solidifies its importance. Journal of Educational Psychology, 101(4), 817. https://doi.org/10.1037/a0016127

\section{Copyrights}

Copyright for this article is retained by the author, with first publication rights granted to the journal.

This is an open-access article distributed under the terms and conditions of the Creative Commons Attribution license (http://creativecommons.org/licenses/by/4.0/). 